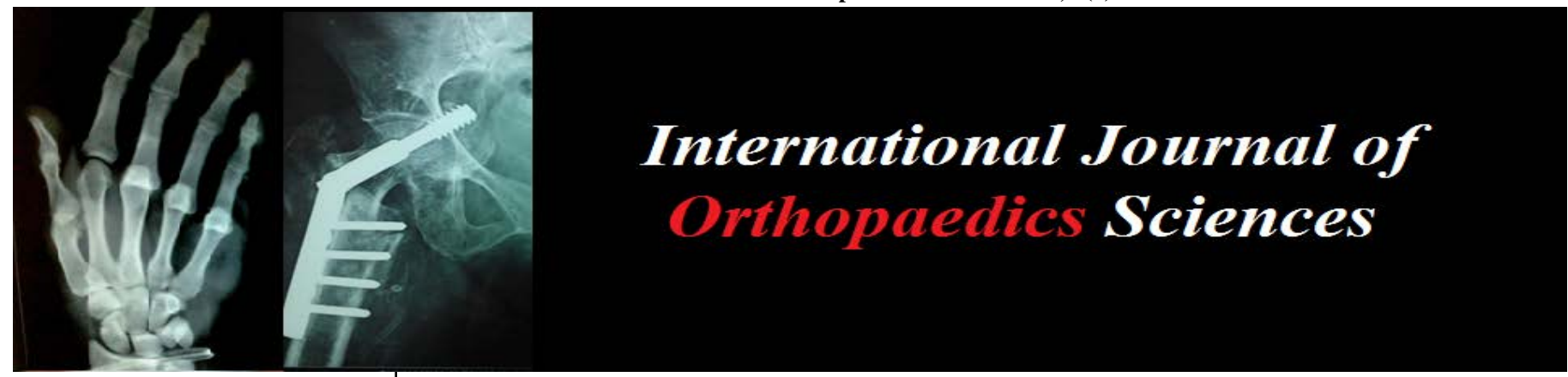

E-ISSN: 2395-1958

P-ISSN: 2706-6630

IJOS 2021; 7(3): 737-742

(C) 2021 IJOS

www.orthopaper.com

Received: 10-05-2021

Accepted: 12-06-2021

\section{Ashok Singla}

Associate Professor and Head of

Microbiology, Department of

Microbiology, Govt Medical

College, Patiala, India

Deepak Goyal

Senior Resident,

Department of Orthopaedics,

Government Medical College,

Patiala, India

KS Sandhu

Professor and Head,

Department of Orthopaedics,

Government Medical College,

Patiala, India

Karamdeep Singh Kahal

Senior Resident,

Department of Orthopaedics,

Government Medical College,

Patiala, India

\section{Dharmpal}

Senior Resident,

Department of Orthopaedics, Government Medical College,

Patiala, India

Corresponding Author:

Deepak Goyal

Senior Resident,

Department of Orthopaedics,

Government Medical College,

Patiala, India

\section{Comparison of the results of expert tibial nailing with results of distal tibial plating in patients with distal $1 / 3$ rd extraarticular tibial fractures}

\author{
Ashok Singla, Deepak Goyal, KS Sandhu, Karamdeep Singh Kahal and \\ Dharmpal
}

DOI: https://doi.org/10.22271/ortho.2021.v7.i3k.2826

Abstract

Background: The tibia constitutes one of two bones of the leg. Recently, minimally invasive percutaneous medial locked plating has been described in the literature with promising results. Expert Tibial Nail currently represents an effective approach to the treatment of complex extraarticular distal tibial fractures. Hence; the present study was undertaken for comparing the results of Expert Tibial nailing with results of Distal Tibial Plating in patients with Distal 1/3rd extraarticular Tibial Fractures.

Materials \& Methods: The study was conducted on 40 patients with extraarticular distal $1 / 3^{\text {rd }}$ tibia fractures. All the patients were divided into two study groups randomly with 20 patients in each group as follows: Expert Tibial Nailing group, \& Distal Tibial Plating group. All the patients underwent procedures according to their respective study groups. During the postoperative phase, static quadriceps exercises \& toe movements, as tolerated were started from 1st postoperative day. Full weight-bearing was allowed after 10 to 12 weeks, depending on the radiographic signs of fracture healing. Patients were followed up for 6 months after operation and evaluated as per Johner and Wruss Criteria.

Results: The mean age of the patients of the expert tibial nailing group and distal tibial plating group was 48.12 years and 49.71 years respectively. Mean operative time among the patients of the expert tibial nailing group was 83.15 minutes and was significantly lower in comparison to the patients of the distal tibial plating group (101.2 minutes). Mean intraoperative blood loss was compared between expert tibial nailing and distal tibial plating. Torniquet was used in all the cases. Mean intraoperative blood loss among the patients of the expert tibial nailing group was $51.6 \mathrm{ml}$ and was significantly lower in comparison to the patients of the distal tibial plating group $(89.1 \mathrm{ml})$. Mean postoperative weight-bearing time among the patients of expert tibial nailing was 8.95 weeks and was significantly lower in comparison to the patients of the distal tibial plating (14.35 weeks). Mean fracture union time among the patients of the expert tibial nailing group was 18.6 weeks and was significantly lower in comparison to the patients of the distal tibial plating group (25.84 weeks). Excellent results were obtained in 80 percent of the patients of the expert tibial nailing group and 55 percent of the patients of the distal tibial plating group respectively.

Conclusion: The results of present study with expert tibial interlocking nailing are encouraging and demonstrate the benefits of new nailing system. Changes in the design of the nail for improved proximal and distal locking enable it to use in proximal and distal metaphyseal fractures of tibia.

Keywords: distal tibial plating, expert tibial nailing, tibial fractures

\section{Introduction}

The tibia constitutes one of two bones of the leg. Since it is weight-bearing bone, it is suggestively superior and tougher in comparison to fibula. The proximal component of the tibia comprises of a medial and lateral condyle. These join to form knee joint's inferior portion. Intercondylar portion lies in between the two condyles. It is this particular area where the anterior cruciate ligament, posterior cruciate ligament, and menisci have their attachments. The tibial shaft is tersely widened at its higher end to support the condyles ${ }^{[1-3]}$.

Fractures of the distal tibia are distressing because these occur mainly because of high-energy mechanisms and vehicles. Because of the complex nature, fractures of distal tibia and pilon are difficult to manage. In combination with crucial bone injury, the adjacent soft tissue components often become severely traumatized. 
Major component of the tibial fractures are closed in nature ${ }^{[4,}$ 5].

Since last couple of decades, four different approaches have been employed for managing tibial fractures. These include intramedullary nail fixation (interlocking intramedullary nails and simple intramedullary rods), plate fixation, external fixation, and casting or functional bracing. In majority proportion of the unstable fracture patterns, surgeons usually prefer not using casts as they do not maintain adequate fracture alignment. From past few years, an increasing trend of using intramedullary nailing has been the treatment of preference among surgeons for managing both closed and open tibial fractures ${ }^{[6-8]}$.

Open reduction and plating is a popular method that can result in good fixation. Recently, minimally invasive percutaneous medial locked plating has been described in the literature with promising results. Intramedullary fixation is desirable as it is less invasive, load sharing spares extraosseous blood supply, and fracture hematoma. Expert Tibial Nail currently represents an effective approach to the treatment of complex extraarticular distal tibial fractures ${ }^{[6-8]}$. Hence; the present study was undertaken for comparing the results of Expert Tibial nailing with results of Distal Tibial Plating in patients with Distal 1/3rd extraarticular Tibial Fractures.

\section{Materials \& Methods}

The study was conducted on 40 patients with extraarticular distal 1/3rd tibia fractures in the Department of Orthopaedics, Government Medical College, and Rajindra Hospital, Patiala. Patients who satisfied inclusion criteria were included in the study after taking informed consent. The patients were divided into two groups randomly i.e, group A and group B with 20 cases in each group. Patients in Group A were treated with Expert tibial nailing and patients in Group B were treated with open reduction and internal fixation (ORIF) using distal tibia plating.

A total of 40 patients were selected from the emergency / OPD in the Department of Orthopaedics, Government Medical College, and Rajindra Hospital, Patiala.

\section{Inclusion criteria}

- Skeletally mature patients

- Extrarticular fractures of distal tibia (Simple, wedge, complex or segmental)

- Patient presenting within 2 weeks after sustaining injury/trauma

\section{Exclusion Criteria}

- Comminuted and intraarticular fractures

- $\quad$ Grade III (B,C )open fractures

- Skeletally immature patients

- Patients with vascular injury

- Patients with significant comorbidities and medically unfit for surgery

- Patients presenting after 2 weeks of sustaining injury or trauma

Patients were given first aid in the form of splintage of the limb, anti-inflammatory drugs, and analgesics according to the need. Any accompanying fresh injury or illness was noted and managed accordingly. The name of the patient, age of the patient, and sex of the patient was recorded routinely. The occupation of the patient was noted, and this is considered an important deciding factor in the early rehabilitation of the patient to his work. An initial detailed history of the patient, which included mode and nature of injury, conscious level, any treatment history, signs of shock and any emergency treatment taken were recorded. A complete clinical examination of the patient was done and the patient was admitted to the ward. In the history, symptoms of pain, swelling, abnormal mobility, deformity, loss of function were recorded. Pain perception may vary according to the fracture, whether fresh or old fracture, with pain severity being more in fresh fractures. Swelling is associated with a fracture and was mentioned. Abnormal mobility was noted. The deformity was also noted in the presenting complaint. The patient with fracture shaft of the tibia having loss of function is indicated. General physical examination and investigations were done as per the performa attached. Pre-operative counseling of the patient and his relatives regarding the method of treatment and prognosis was done and consent was taken. All the patients were divided into two study groups randomly with 20 patients in each group as follows:

- Expert Tibial Nailing group

- Distal Tibial Plating group

All the patients underwent procedures according to their respective study groups. During the postoperative phase, static quadriceps exercises \& toe movements, as tolerated were started from 1st postoperative day. Ankle mobilization was started from 3rd postoperative day. Intravenous antibiotics were given for 3-5 days followed by a course of oral antibiotics for 5 days. Analgesics were given as per need. Suture removal was done on the 11th Postoperative day. Protected weight-bearing was allowed once signs of progress toward union were evident on radiographs, usually at 6 weeks postoperatively. Full weight-bearing was allowed after 10 to 12 weeks, depending on the radiographic signs of fracture healing. X-rays were taken at regular intervals and evaluated for fracture healing, alignment at fracture site \& for any evidence of mal-alignment. Patients were followed up for 6 months after operation and evaluated as per Johner and Wruss Criteria. All the results were summarized in a Microsoft excel sheet and were analyzed by SPSS software. Chi-square test, unpaired t-test, and Mann Whitney $U$ test was used for assessment of the level of significance. P-value of less than 0.05 was taken as significant.

\section{Results}

The mean age of the patients of the expert tibial nailing group and distal tibial plating group was 48.12 years and 49.71 years respectively. 80 percent of the patients with the expert tibial nailing and 70 percent of the patients with distal tibial plating were males while the remaining were females. In 60 percent of the patients of the expert tibial nailing group and 65 percent of the patients of the distal tibial plating group, the right side was involved. Road traffic accident was the mode of injury in 60 percent of the patients of the expert tibial nailing group and 70 percent of the patients of the distal tibial plating group respectively. In the remaining patients of both the study groups, fall was the etiologic factor. Mean operative time among the patients of the expert tibial nailing group was 83.15 minutes and was significantly lower in comparison to the patients of the distal tibial plating group (101.2 minutes). Mean intraoperative blood loss was compared between expert tibial nailing and distal tibial plating. Torniquet was used in all the cases. Mean intraoperative blood loss among the patients of the expert tibial nailing group was $51.6 \mathrm{ml}$ and was significantly lower in comparison to the patients of the distal tibial plating group $(89.1 \mathrm{ml})$. Mean postoperative weight- 
bearing time among the patients of expert tibial nailing was 8.95 weeks and was significantly lower in comparison to the patients of the distal tibial plating (14.35 weeks). Mean fracture union time among the patients of the expert tibial nailing group was 18.6 weeks and was significantly lower in comparison to the patients of the distal tibial plating group (25.84 weeks). Excellent results were obtained in 80 percent of the patients of the expert tibial nailing group and 55 percent of the patients of the distal tibial plating group respectively. Good results were obtained in 10 percent of the patients of the expert tibial nailing group and 30 percent of the patients of the distal tibial plating group respectively. Non union, malunion and delayed union was seen in 5 percent, 5 percent and 10 percent patients with distal tibia plating respectively, while it was 0 percent, 10 percent and 5 percent respectively in patients with Expert Tibia Nailing. Rate of infection was 15 percent in distal tibia plating compared to 5 percent in expert tibia nailing. Anterior knee pain was seen in 15 percent patients of expert tibia nailing and no patient of distal tibia plating had anterior knee pain. Mean hospital stay among the patients of the expert tibial nailing group was 7.5 days and was significantly lower in comparison to the patients of the distal tibial plating group (11.25 days).
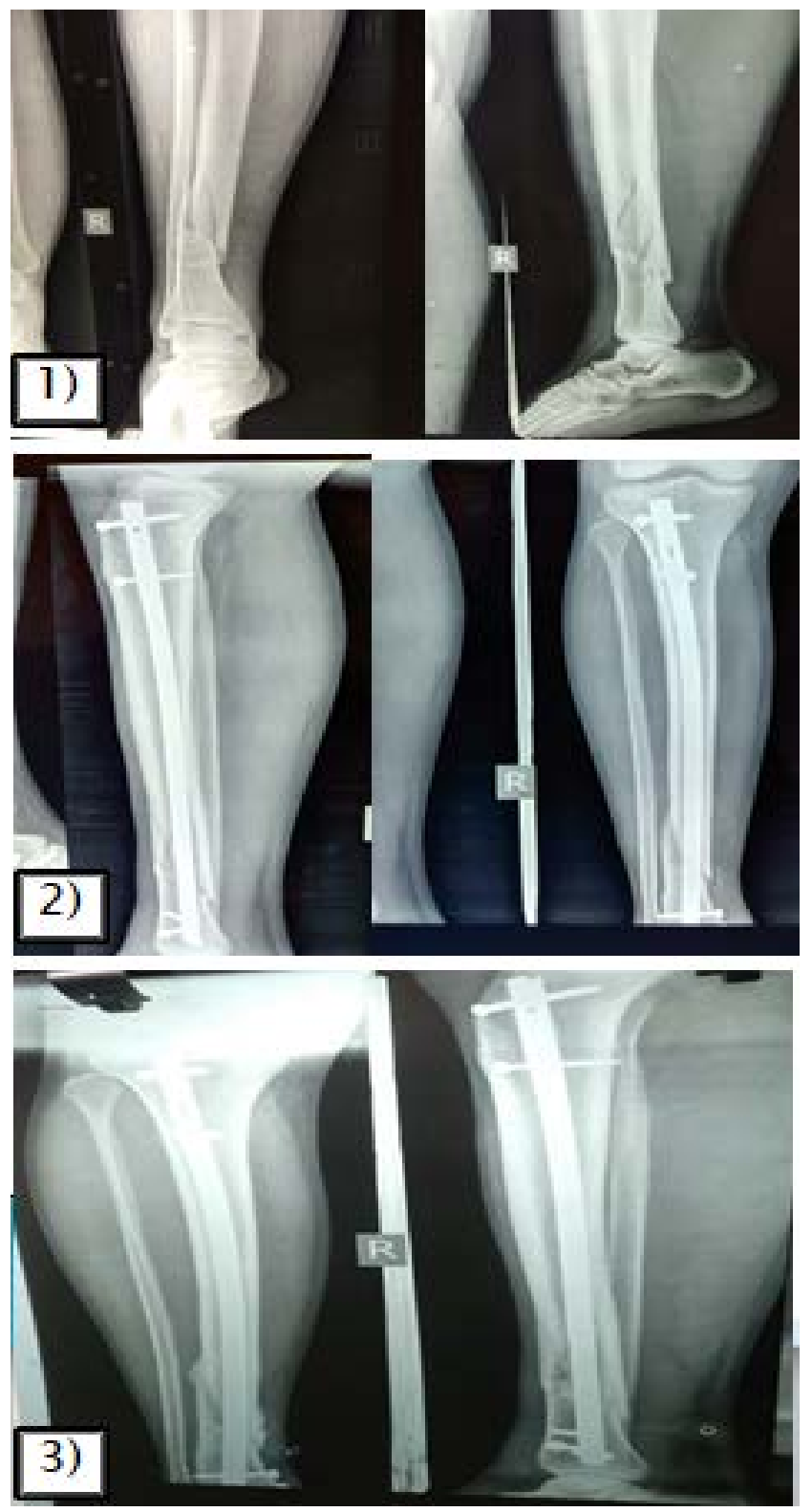

Fig 1: Case 1- Preoperative X-Ray, 2) Postoperative X-ray, and 3) Follow-up X-ray at 12 weeks

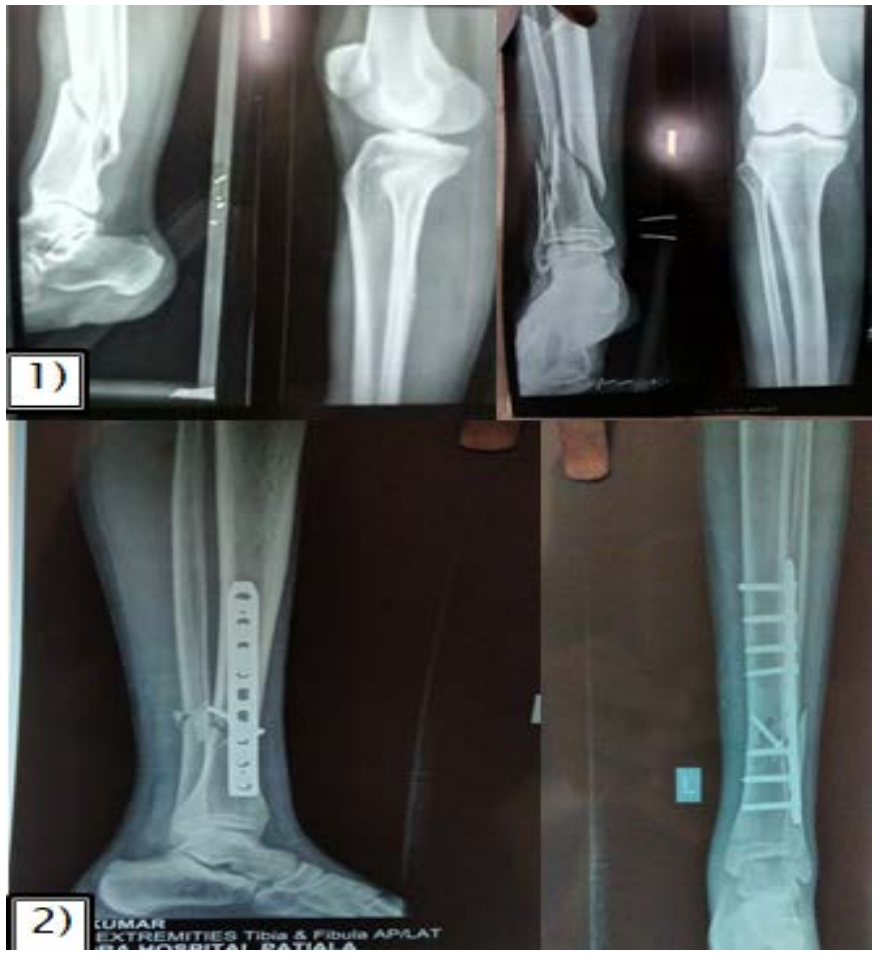

Fig 2: Case 1- Preoperative X-Ray, 2) Postoperative X-ray

Table 1: Comparison of mean operative time (minutes)

\begin{tabular}{|c|c|c|}
\hline $\begin{array}{c}\text { Operative time } \\
\text { (minutes) }\end{array}$ & $\begin{array}{c}\text { Expert Tibial } \\
\text { Nailing }\end{array}$ & $\begin{array}{c}\text { Distal Tibial } \\
\text { Plating }\end{array}$ \\
\hline Mean & 83.15 & 101.2 \\
\hline SD & 10.02 & 7.52 \\
\hline p- value & \multicolumn{2}{|c|}{0.00} \\
\hline
\end{tabular}

Table 2: Comparison of intraoperative blood loss

\begin{tabular}{|c|c|c|}
\hline $\begin{array}{c}\text { Intraoperative blood loss } \\
\text { (ml) }\end{array}$ & $\begin{array}{c}\text { Expert Tibial } \\
\text { Nailing }\end{array}$ & $\begin{array}{c}\text { Distal Tibial } \\
\text { Plating }\end{array}$ \\
\hline Mean & 51.6 & 89.1 \\
\hline SD & 18.4 & 10.61 \\
\hline p- value & \multicolumn{2}{|c|}{0.01} \\
\hline
\end{tabular}

Table 3: Comparison of postoperative weight bearing (full weight bearing)

\begin{tabular}{|c|c|c|}
\hline $\begin{array}{c}\text { Post-operative full weight } \\
\text { bearing (weeks) }\end{array}$ & $\begin{array}{c}\text { Expert Tibial } \\
\text { Nailing }\end{array}$ & $\begin{array}{c}\text { Distal Tibial } \\
\text { Plating }\end{array}$ \\
\hline Mean & 8.95 & 14.35 \\
\hline SD & 1.14 & 2.25 \\
\hline p- value & \multicolumn{2}{|c|}{0.02} \\
\hline
\end{tabular}

Table 4: Comparison of fracture union time (weeks)

\begin{tabular}{|c|c|c|}
\hline $\begin{array}{c}\text { Fracture union time } \\
\text { (weeks) }\end{array}$ & $\begin{array}{c}\text { Expert Tibial } \\
\text { Nailing }\end{array}$ & $\begin{array}{c}\text { Distal Tibial } \\
\text { Plating }\end{array}$ \\
\hline Mean & 18.6 & 25.84 \\
\hline SD & 1.27 & 3.94 \\
\hline p- value & \multicolumn{2}{|c|}{0.003 (Significant) } \\
\hline
\end{tabular}

Table 5: Outcome

\begin{tabular}{|c|c|c|c|c|}
\hline \multirow{2}{*}{$\begin{array}{c}\text { Johner - } \\
\text { Wruss } \\
\text { scoring } \\
\text { System }\end{array}$} & $\begin{array}{c}\text { Expert Tibial Nailing } \\
\text { of } \\
\text { patients }\end{array}$ & Percentage & $\begin{array}{c}\text { Dumber } \\
\text { of } \\
\text { patients }\end{array}$ & Percentage \\
\hline Excellent & 16 & 80 & 11 & 55 \\
\hline Good & 2 & 10 & 6 & 30 \\
\hline Fair & 2 & 10 & 2 & 10 \\
\hline Poor & 0 & 0 & 1 & 5 \\
\hline Total & 20 & 100 & 20 & 100 \\
\hline p- value & \multicolumn{4}{|c|}{0.00} \\
\hline
\end{tabular}




\section{Discussion}

Fractures of the distal tibia occur commonly, afflicting all ages. On one end of the spectrum, low-energy falls generate torsional spiral fractures of the metaphysis and distal diaphysis, whereas, on the other extreme, the high-energy blunt impact causes complex comminuted fractures. Even with the least severe fractures, the overlying soft tissue envelope is problematic because the anteromedial cortex of the tibia is subcutaneous ${ }^{[7-10]}$.

In skeletally mature patients, displaced distal tibia fractures are treated surgically to provide better fracture alignment, pain relief, support for local soft tissues, and to promote mobility of the adjacent joints. Plates and intramedullary nails are both frequently used in this location, and each performs reliably, with a similar restoration of function. The composite of published literature to date suggests both methods have low rates of primary infection and modest, comparable rates of a primary union, with a tendency for more malalignment associated with infrapatellar nails. Surgeons have personal preferences in implant selection and technique, largely based on their training and experience. However, treatment of distal tibia fractures with both plates and nails should be familiar to all, including an understanding of results and outcomes of large studies, to optimize care of the injured patient [7-10] Hence; the present study was undertaken for comparing the results of Expert Tibial nailing with results of Distal Tibial Plating in patients with Extraarticular Distal 1/3rd Tibial Fractures.

In the present study, the mean age of the patients of the Expert Tibial Nailing group and the Distal Tibial Plating group was 48.12 years and 49.71 years respectively. The majority of the patients of both the study group belonged to the age group of 41 to 60 years. These age groups are more common as they are physically active persons, were engaged in increased various outdoor activities and as a result, most of the injuries sustained were high-velocity injuries. Both the groups were comparable in terms of the age-wise distribution of patients. Our results were in concordance with the results obtained by Vallier et al. (2011), Sharma et al. (2019), and Gupta et al. (2010) who also reported similar findings in their respective studies. In a study conducted by Gupta VSK et al the patients were aged 23 - 65 years with fractures being most common during their 4th and 5th decade of life ${ }^{\text {[11-13] }}$

80 percent of the patients of the Expert Tibial Nailing group and 70 percent of the patients of the Distal Tibial Plating group were males while the remaining were females. Both the study groups were comparable in terms of gender-wise distribution of patients. Our results were in concordance with the previous authors who also reported male preponderance in their respective studies. In a study conducted by Gupta et al. (2010), majority of patients were males, 37 (66\%) and there were 19 (34\%) females. Predominant involvement of male gender in both the groups can be explained, as males are more frequently exposed to outdoor activities and hence more involved in road side accidents, industrial misfortunes and assaults ${ }^{[13]}$.

In 60 percent of the patients of the Expert Tibial Nailing group and 65 percent of the patients of the Distal Tibial Plating group, the right side was involved while in the remaining patients, left side involvement occurred. Higher involvement of the right side can probably be because most of the population is right-handed and as a protective reflex mechanism, use dominant limb for self-protection during trauma. Our results were in concordance with the results obtained by Gupta et al. (2010) and Soni et al. (2018) who also reported higher involvement of right side involvement in their respective studies ${ }^{[13,14]}$.

The mean operative time of the patients of the expert tibial nailing group was 83.15 minutes and was significantly lower in comparison to the distal tibial plating group (101.2 minutes). Shorter operative time in the expert tibial nailing group can be probably due to the fact that smaller incisions are required in nailing and the fact that the need for anatomical reduction is not indicated. Our results were in concordance with the result obtained in the past literature where authors have reported significantly higher operative time among the patients of the plating group in comparison to the nailing group. Mean operative time in the study conducted by Zhu et al. (2015) among the patients of the nailing group and the plating group was 84.5 minutes and 95.7 minutes respectively. In the study conducted by Raj et al. (2019) the mean operative time among the patients of the nailing group and plating group was 72.19 minutes and 98.13 minutes respectively $[15,16]$.

Intraoperative blood loss was $89.1 \mathrm{ml}$ in the distal tibial plating group and was significantly higher in comparison to the expert tibial nailing group $(51.6 \mathrm{ml})$ even with the use of torniquet in all the cases. This can probably be attributed to the fact that the fracture site is not opened and smaller incisions with less soft tissue dissection are used in nailing compared to plating. The blood loss was calculated by evaluation of preoperative and postoperative hemoglobin values. Our results were in concordance with the result obtained by Zhu et al. (2015), where authors reported that mean blood loss was significantly higher among patients of the plating group $(108 \mathrm{ml})$ in comparison to the patients of the nailing group $(51.6 \mathrm{ml})^{[15]}$.

Plating significantly disrupts the extraosseous blood supply of the tibia. Plating might prevent periosteal vessels from filling and functioning properly. It can be correlated with poor healing of the wound, as well as the fracture site, and may ultimately require further intervention if healing is not obtained $^{[17]}$.

The mean postoperative full weight-bearing was 8.95 weeks in the expert tibial nailing group and was significantly lower in comparison to the distal tibial plating group where the mean postoperative full weight-bearing was 14.35 weeks. This can be attributed to the fact that strength and load sharing is more in the intramedullary nail as compared to plating so patients can be made to walk earlier. Our results were in concordance with the results obtained by Zhu et al. (2015), where authors have also reported similar findings. Mean postoperative weight-bearing among the patients of the nailing group and plating group within the study under consideration was 8.4 weeks and 12 weeks respectively ${ }^{[15]}$.

Mean fracture union time was 18.6 weeks in patients of the expert tibial nailing group and was 25.84 weeks in distal tibial plating group. While comparing statistically, significant results were obtained. The majority of the results reported in the past literature by various authors support the findings of the present study. Yang et al. (2006) also reported significantly lesser fracture union time in the nailing group (22.6 weeks) in comparison to the plating group (27.8 weeks) [18]. In another study conducted by Soni et al. (2018), the mean fracture union time among the patients of the expert nailing group was 19.25 weeks and was significantly higher in comparison to the patients of the plating group (27.8 weeks) [14]. Zhu et al. (2015), in their study, reported significantly lower fracture union time among the patients of the nailing group (17.6 weeks) in comparison to the plating group (25.8 
weeks) ${ }^{[15]}$.

Expert intramedullary nails prove to be a better option for the treatment of distal third metaphyseal tibia fractures due to multiple locking options thus providing additional rotational stability. Multidirectional interlocking screws ensure that alignment can be well maintained and stability preserved despite short proximal or distal fragments. Studies conducted by Gregory and Sanders (85.10\%) and Krettek et al. (1995), $71 \%$ showed the same observations ${ }^{[19]}$. In a study conducted by Duwelius et al. (1995), 80\% of the cases showed radiological and clinical union between 8-10 weeks following expert nail and the remaining $20 \%$ of patients achieved union between 10-12 weeks. Blachut et al. (1997) in their series of 64 fractures have reported the average time for the radiological union to be 9 weeks ${ }^{[20]}$.

Mean hospital stay among the patients of expert tibial nailing group and distal tibial plating group was 7.5 days and 11.25 days respectively. Significant results were obtained while comparing the mean hospital stay among the patients of both the study groups. Shorter hospital stay in expert tibial nailing group can be because nailing required fewer dressings and lesser antibiotics compared to plating so the patient could be discharged earlier safely. Our results were in concordance with the results obtained by $\mathrm{Li}$ et al where authors also reported a significantly shorter duration of hospital stay among the patients of the nailing group (5.8 days) in comparison to the patients of the plating group (8.9 days) ${ }^{[21]}$. According to the Johner - Wruss scoring System, in the expert tibial nailing group, excellent results were obtained in 80 percent of the patients while good and fair results were obtained in 10 percent of the patients each respectively. In the distal tibial plating group, excellent results were obtained in 55 percent of the patients, good results were obtained in 30 percent of the patients, while fair and poor results were seen in 10 percent and 5 percent of the patients respectively. Although non-significant, better results were observed in the nailing group. Our results were in concordance with the results obtained in previous studies where authors have also reported similar findings. In the study conducted by Zhu et al (2015), good to excellent results were seen in 90.32 percent of the patients of the nailing group and 77.27 percent of the patients of the plating group ${ }^{[15]}$. In another study conducted by Soni et al, (2018) good to excellent results were seen in 86.66 percent of the patients of the nailing group and 80 percent of the patients of the plating group ${ }^{[14]}$. Similar findings were reported in the study conducted by Chaudhari et al. (2018), where authors also obtained good to excellent results in 81 percent of the patients of the nailing group and 89 percent of the patients of the plating group. ${ }^{22}$ Nandakumar et al. (2015) concluded that intramedullary interlocking nailing is a reliable method of treatment for distal metaphyseal tibial fractures with a high union rate and low complication rate ${ }^{[23]}$.

\section{Conclusion}

The results of present study with expert tibial interlocking nailing are encouraging and demonstrate the benefits of new nailing system. Changes in the design of the nail for improved proximal and distal locking enable it to use in proximal and distal metaphyseal fractures of tibia. Contemporary nail designs also include locking options in three planes, which allow a better stabilization of small proximal and distal fragments and obtain a higher stability of the bone implant construct. The results were however comparable for both with a slight edge to expert tibia nailing in terms of decreased fracture union time and early weight bearing and less chances of infection and wound complications over distal tibia plating. We recommend the use of expert tibial nail in metaphyseal and diaphyseal fractures of the tibia.

\section{References}

1. Gupton M, Terreberry RR. Anatomy, bony pelvis and lower limb, knee. StatPearls [Internet] 2020.

2. Hallock GG, Anous MM, Sheridan BC. The surgical anatomy of the principal nutrient vessel of the tibia. Plastic and reconstructive surgery 1993;92(1):49-54.

3. Russo A, Reginelli A, Zappia M, Rossi C, Fabozzi O, Cerrato M, Macarini L et al. Ankle fracture: radiographic approach according to the Lauge-Hansen classification. Musculoskeletal surgery 2013;97(2):155-60.

4. Rodziewicz TL, Hipskind JE. StatPearls [Internet] StatPearls Publishing. Treasure Island (FL): 2020, 5.

5. Madadi F, Eajazi A, Madadi F, Besheli LD, Sadeghian R, Lari MN. Adult tibial shaft fractures-different patterns, various treatments and complications. Medical science monitor: international medical journal of experimental and clinical research 2011;17(11):CR640.

6. Galbraith RM, Lavallee ME. Curr Rev Musculoskelet Med 2009;2(3):127-33. doi: 10.1007/s12178-009-9055-6. Medial tibial stress syndrome: conservative treatment options.

7. Venkatesh Reddy D, Krishna S, Wooly S. A clinical profile of patients with distal tibia fractures attending tertiary care hospital. International Journal of Orthopaedics 2017;3(3):113-5.

8. Gray $\mathrm{H}$, Lewis WH. Anatomy of the human body. Philadelphia: Lea \& Febiger; 1918. Online edition Bartleby. com 2000.

9. Madadi F, Eajazi A, Madadi F, Besheli LD, Sadeghian R, Lari MN. Adult tibial shaft fractures-different patterns, various treatments and complications. Medical science monitor: international medical journal of experimental and clinical research 2011;17(11):CR640.

10. Puno RM, Teynor JT, Nagano J, Gustilo RB. Critical analysis of results of treatment of 201 tibial shaft fractures. Clinical orthopaedics and related research 1986;(212):113-21.

11. Cheng W, Li Y, Manyi W. Comparison study of two surgical options for distal tibia fracture-minimally invasive plate osteosynthesis vs. open reduction and internal fixation. International orthopaedics 2011;35(5):737-42.

12. Sharma SCC, Sharma S, Sudan S. Treatment of Fracture Distal Tibia by Distal Tibial Locking Plate Verses Interlocking Nail: A Prospective Comparative Study. Int J Med Res Prof 2019;5(1):71-76

13. Gupta RK, Rohilla RK, Sangwan K, Singh V, Walia S. Locking plate fixation in distal metaphyseal tibial fractures: series of 79 patients. International orthopaedics 2010;34(8):1285-90.

14. Soni K, Patel J. Comparative Study of Distal Tibia Fractures managed by nailing vs plating. National Journal of Clinical Orthopaedics 2018;2(3):106-12.

15. Zhu DC, Liu L, Gao F, Li Q, Zhang B. Comparison of closed reduction and expert tibial nailing with open reduction and plate and screw fixation in the treatment of two segmental tibial fractures. Chinese Journal of Traumatology 2015;18(4):219-22.

16. Raj RKM, Kumar NR, Manoharan M. Comparison of functional outcome between expert tibial nail and distal 
tibial medial locking plate by mippo technique for closed extra articular distal tibial fracture. International Journal of Orthopaedics Sciences 2019;5(3):257-262.

17. Borrelli Jr J, Prickett W, Song E, Becker D, Ricci W. Extraosseous blood supply of the tibia and the effects of different plating techniques: a human cadaveric study. Journal of orthopaedic trauma 2002;16(10):691-5.

18. Yang SW, Tzeng HM, Chou YJ, Teng HP, Liu HH, Wong CY. Treatment of distal tibial metaphyseal fractures: plating versus shortened intramedullary nailing. Injury 2006;37(6):531-5.

19. Krettek C, Schandelmaier P, Tscherne H. Nonreamed interlocking nailing of closed tibial fractures with severe soft tissue injury. Clinical orthopaedics and related research 1995;(315):34-47.

20. Blachut PA, O'brien PJ, Meek R, Broekhuyse HM. Interlocking intramedullary nailing with and without reaming for the treatment of closed fractures of the tibial shaft. A prospective, randomized study. JBJS 1997;79(5):640.

21. Li A, Wei Z, Ding $\mathrm{H}$, Tang $\mathrm{H}$, Liu $\mathrm{Y}$, Shi $\mathrm{J}$ et al. Minimally invasive percutaneous plates versus conventional fixation techniques for distal tibial fractures: A meta-analysis. International Journal of Surgery 2017;38:52-60.

22. Chaudhari K. A comparative study of surgical management of distal tibial fractures treated by locking compression plate by minimally invasive percutaneous plate osteosynthesis (MIPPO) and expert tibial nail. EC Orthopedics 2018;9:702-14.

23. Nandakumar R, Mahapatra S. Use of Intramedullary Nail in Distal Metaphyseal Fractures of Tibia. Int J Sci Stud 2015;3(9):4. 